\title{
LOCUS OF CONTROL: PENGENDALIAN DIABETES MELITUS PADA PENDERITA DM TIPE 2
}

\author{
Yusran Haskas ${ }^{*}$, Suryanto \\ ${ }^{1}$ Departemen Keperawatan, Sekolah Tinggi Ilmu Kesehatan Nani Hasanuddin Makassar \\ Jl. Perintis Kemerdekaan VIII No. 24; Makassar; Sulawesi Selatan
}

\begin{abstract}
Abstrak
Tingginya prevalensi penderita diabetes melitus di Indonesia mengharuskan adanya upaya pengendalian diabetes melitus yang dilakukan agar dapat meningkatkan derajat kesehatan. Tujuan penelitian ini adalah mengidentifikasi upaya pelaksanaan pengendalian diabetes melitus yang dilakukan penderita diabetes melitus tipe 2 berdasarkan background factor (personality traits, pendidikan, pengalaman, pengetahuan dan status ekonomi) terkait locus of control yang dimiliki. Jenis penelitian explanatory research dengan desain cross-sectional. Jumlah sampel sebesar 143 responden. Pengujian dilakukan menggunakan uji regresi linear berganda dengan metode backward. Hasil uji statistik menunjukkan bahwa personality traits berpengaruh signifikan terhadap locus of control penderita diabetes melitus $(\alpha=0.06, \rho=0.004)$, pendidikan berpengaruh tidak signifikan terhadap locus of control penderita diabetes melitus $(\alpha=0.06, \rho=0.919)$, pengalaman berpengaruh signifikan terhadap locus of control penderita diabetes melitus $(\alpha=0.06, \rho=0.043)$, pengetahuan berpengaruh tidak signifikan terhadap locus of control penderita diabetes melitus $(\alpha=$ $0.06, \rho=0.640$ ) dan status ekonomi berpengaruh tidak signifikan terhadap locus of control penderita diabetes melitus $(\alpha=0.06, \rho=0.119)$. Berdasarkan background factor yang dilihat, determinan yang berpengaruh signifikan terhadap locus of control penderita diabetes melitus dalam upaya mengendalikan diabetes melitus adalah personality traits dan pengalaman. Locus of control yang lebih dominan adalah internal locus of control.
\end{abstract}

Kata kunci: Diabetes Mellitus Tipe 2; Locus of control; Determinan DM

\begin{abstract}
[LOCUS OF CONTROL: CONTROL OF DIABETES MELITUS IN PATIENTS TYPE 2 DM] The high prevalence of people with diabetes mellitus in Indonesia requires the control of diabetes mellitus to be carried out in order to improve health status. This control effort is very important especially for people with type 2 diabetes mellitus. These efforts can be realized depending on the background factor and locus of control that the patient has related to controlling diabetes mellitus. The purpose of this study was to identify efforts to control diabetes mellitus by type 2 diabetes mellitus patients based on background factors (personality traits, education, experience, knowledge and economic status) related to locus of control possessed. Type of explanatory research with cross-sectional design. Determinant of sample size using sampling techniques by consecutive sampling so that the number of samples was 143 respondents. The results of statistical tests show that personality traits have a significant effect on locus of control of diabetes mellitus patients $(\alpha=0.06, \rho=0.004)$, education has no significant effect on locus of control of diabetics ( $\alpha=0.06$, $\rho=0.919)$, experience has a significant effect to locus of control of diabetes mellitus sufferers ( $\alpha=0.06$, $\rho=0.043$ ), knowledge has no significant effect on locus of control of diabetes mellitus sufferers $(\alpha=0.06, \rho=0.640)$ and economic status has no significant effect on locus of control of diabetes mellitus sufferers $(\alpha=0.06, \rho=0.119)$. Based on the background factors seen, the determinants that significantly influence the locus of control of patients with diabetes mellitus in an effort to control diabetes mellitus are personality traits and experiences. The more dominant locus of control is internal locus of control.
\end{abstract}

Keywords: Diabetes Mellitus Tipe 2; Locus of control; Determinan DM

*)Yusran Haskas

E-mail: yusranhaskas@stikesnh.ac.id 


\section{Pendahuluan}

Diabetes melitus (DM) merupakan penyakit yang prevalensinya selalu mengalami peningkatan. Secara global diperkirakan sekitar 364 juta orang menderita diabetes, dengan data tahun 2002 terdapat 150 juta penduduk dunia yang menderita DM dan meningkat pada tahun 2005 menjadi 220 juta penduduk dunia (WHO, 2015). Mengingat peningkatan yang terus terjadi, maka upaya pengendalian DM menjadi hal yang sangat penting untuk diterapkan.

Pengendalian DM merupakan salah satu faktor yang dapat membuat tingkat kesembuhan penyakit menjadi lebih baik. Dimana tujuan pengendalian DM adalah antara lain menghilangkan gejala; menciptakan dan mempertahankan rasa sehat; memperbaiki kualitas hidup; mencegah komplikasi akut dan kronik; mengurangi laju perkembangan komplikasi yang ada; mengurangi kematian; dan mengobati penyakit penyerta bila ada (Soegondo, 2015). Berdasarkan tujuan tersebut diharapkan dapat timbul sebuah perilaku pengendalian DM.

Background factor diketahui dapat mempengaruhi sikap dan perilaku individu terhadap sesuatu. Hal tersebut merupakan sifat yang pada dasarnya hadir dalam diri seseorang. Ada tiga faktor dalam background factor individu antara lain yaitu personal, sosial dan informasi. Faktor personal seperti personality traits, value, emosi dan kecerdasan. Faktor sosial seperti usia, jenis kelamin, etnis, pendidikan, penghasilan dan agama. Faktor informasi seperti pengalaman, pengetahuan dan ekspose pada media (Ajzen, 2014)

Selain background factor, locus of control juga memiliki hubungan yang besar akan terciptanya perilaku, dimana seorang individu akan menerima berbagai kejadian sebagai bagian dari perilaku atau karakteristiknya sendiri (Rotter, 1966). Locus of control kemudian berperan ketika individu akan memprediksikan berbagai faktor yang dapat mendukung terciptanya sebuah perilaku, baik itu dari faktor internal maupun faktor eksternal (K. Wallston, 2001). Pengendalian diri dan lingkungan luar diketahui sangat berpengaruh dalam tingkat kepatuhan seseorang, untuk itu locus of control sangat berhubungan erat dengan kepatuhan, terutama kepatuhan pengobatan dalam mengendalikan diabetes melitus.

Berdasarkan penelitian K. A. Wallston (1981), konsep locus of control berperan pada saat individu mengumpulkan berbagai faktor yang dapat mendukung terciptanya sebuah perilaku, baik faktor internal ataupun eksternal. Sehingga tujuan dari penelitian ini adalah mengidentifikasi background factor terhadap locus of control yang dimiliki penderita terkait pengendalian diabetes melitus.

\section{Metode}

Jenis penelitian yang digunakan adalah explanatory research yang bertujuan untuk menganalisis hubungan antara satu variabel dengan variabel lainnya, dan menggunakan desain cross-sectional. Penelitian ini dilaksanakan di tiga rumah sakit di Kota Makassar yaitu RS Tk. II Pelamonia, RS Islam Faisal dan RS Kota Makassar, serta lima puskesmas di Kota Makassar yaitu Puskesmas Antang, Puskesmas Antara, Puskesmas Batua, Puskesmas Sudiang Raya dan Puskesmas Tamalanrea Jaya. Penelitian ini dilaksanakan pada bulan Juni sampai Agustus tahun 2017. Populasi penelitian adalah seluruh penderita DM yang berobat ke rumah sakit maupun puskesmas lokasi penelitian. Adapun sampel penelitian dipilih dengan menggunakan teknik consecutive sampling sehingga diperoleh jumlah besar sampel sebesar 143 responden.

$$
\text { Pengumpulan data dilakukan }
$$

menggunakan kuesioner dengan variabel penelitian antara lain yaitu variabel independen background factor dan variabel dependen locus of control. Kuesioner kemudian diuji validitasnya dengan menggunakan analisis korelasi pearson product moment dengan rentang hasil uji validitas antara $0.355-0.456$ dan uji reliabilitas menggunakan alpha cronbach's dengan rentang nilai antara 0.50-0.70 sehingga kuesioner yang dipakai valid dan reliabel. Pengujian hipotesis penelitian dilakukan dengan menggunakan uji regresi linear berganda dengan metode backward dengan nilai $\alpha=0.06$, dimaksudkan agar peluang terjadinya kesalahan dalam pengukuran sebanyak 6 kali atau $6 \%$ dari total pengukuran.

\section{Hasil dan Pembahasan}

Berdasarkan penelitian yang dilakukan, diperoleh hasil sebagai berikut : Tabel 1 . menunjukkan hasil dari distribusi karakteristik responden dengan jumlah paling banyak berada pada kelompok umur 46-55 tahun (35.7\%), berjenis kelamin laki-laki (52.4\%), pendidikan terakhir pada tingkat SMA $(45.5 \%)$, lama menderita DM > 5 tahun (48.3\%), sebagian besar tidak memiliki komplikasi (55.9\%) dan cenderung lebih memiliki internal locus of control $(88.1 \%)$. 
Tabel 1. Distribusi Frekuensi Karakteristik Responden ( $\mathrm{n}=143$ )

\begin{tabular}{|c|c|c|c|c|c|c|}
\hline \multirow{2}{*}{ Karakteristik Responden } & \multicolumn{2}{|c|}{ RS } & \multicolumn{2}{|c|}{ Puskesmas } & \multicolumn{2}{|c|}{ Total } \\
\hline & $\mathbf{n}$ & $\%$ & $\mathbf{n}$ & $\%$ & $\mathbf{N}$ & $\%$ \\
\hline \multicolumn{7}{|l|}{ Kelompok Umur } \\
\hline $26-35$ tahun & 1 & 1,2 & 0 & 0,0 & 1 & 0,7 \\
\hline 36-45 tahun & 15 & 18,5 & 9 & 14,5 & 24 & 16,8 \\
\hline 46-55 tahun & 34 & 42,0 & 17 & 27,4 & 51 & 35,7 \\
\hline 56-65 tahun & 16 & 19,8 & 27 & 43,5 & 43 & 30,1 \\
\hline$>65$ tahun & 15 & 18,5 & 9 & 14,5 & 24 & 16,8 \\
\hline \multicolumn{7}{|l|}{ Jenis Kelamin } \\
\hline Laki-laki & 51 & 63,0 & 24 & 38,7 & 75 & 52,4 \\
\hline Perempuan & 30 & 37,0 & 38 & 61,3 & 68 & 47,6 \\
\hline \multicolumn{7}{|l|}{ Pendidikan Terakhir } \\
\hline $\begin{array}{l}\text { Tidak Sekolah } \\
\end{array}$ & 4 & 4,9 & 3 & 4,8 & 7 & 4,9 \\
\hline SD & 8 & 9,9 & 14 & 22,6 & 22 & 15,4 \\
\hline SMP & 14 & 17,3 & 8 & 12,9 & 22 & 15,4 \\
\hline SMA & 38 & 46,9 & 27 & 43,5 & 65 & 45,5 \\
\hline Diploma dan Sarjana & 17 & 21,0 & 9 & 14,5 & 26 & 18,2 \\
\hline Magister & 0 & 0,0 & 1 & 1,6 & 1 & 0,7 \\
\hline \multicolumn{7}{|l|}{ Lama Menderita DM } \\
\hline$<1$ tahun & 12 & 14,8 & 5 & 8,1 & 17 & 11,9 \\
\hline $1-5$ tahun & 33 & 40,7 & 24 & 38,7 & 57 & 39,9 \\
\hline$>5$ tahun & 36 & 44,4 & 33 & 53,2 & 69 & 48,3 \\
\hline \multicolumn{7}{|l|}{ Komplikasi } \\
\hline Tidak Ada & 44 & 54,3 & 36 & 58,1 & 80 & 55,9 \\
\hline Ada & 37 & 45,7 & 26 & 41,9 & 63 & 44,1 \\
\hline \multicolumn{7}{|l|}{ Locus of Control } \\
\hline Internal & 72 & 88,9 & 54 & 87,1 & 126 & 88,1 \\
\hline External & 9 & 11,1 & 8 & 12,9 & 17 & 11,9 \\
\hline
\end{tabular}

Tabel 2. Dimensi Locus of Control Berdasarkan Umur, Jenis Kelamin, Pendidikan Terakhir, Lama Menderita DM dan Komplikasi ( $\mathrm{n}=143$ )

\begin{tabular}{|c|c|c|c|c|c|c|}
\hline \multirow{3}{*}{ Karakteristik Responden } & \multicolumn{4}{|c|}{ Locus of Control } & \multirow{2}{*}{\multicolumn{2}{|c|}{ Total }} \\
\hline & \multicolumn{2}{|c|}{ Internal } & \multicolumn{2}{|c|}{ External } & & \\
\hline & $\mathbf{n}$ & $\%$ & $\mathbf{n}$ & $\%$ & $\mathbf{n}$ & $\%$ \\
\hline \multicolumn{7}{|l|}{ Kelompok Umur } \\
\hline $26-35$ tahun & 1 & 100,0 & 0 & 0,0 & 1 & 100,0 \\
\hline 36-45 tahun & 21 & 87,5 & 3 & 12,5 & 24 & 100,0 \\
\hline 46-55 tahun & 46 & 90,2 & 5 & 9,8 & 51 & 100,0 \\
\hline 56-65 tahun & 37 & 86,0 & 6 & 14,0 & 43 & 100,0 \\
\hline$>65$ tahun & 21 & 87,5 & 3 & 12,5 & 24 & 100,0 \\
\hline \multicolumn{7}{|l|}{ Jenis Kelamin } \\
\hline Laki-laki & 69 & 92,0 & 6 & 8,0 & 75 & 100,0 \\
\hline Perempuan & 57 & 83,8 & 11 & 16,2 & 68 & 100,0 \\
\hline \multicolumn{7}{|l|}{ Pendidikan Terakhir } \\
\hline Tidak Sekolah & 6 & 85,7 & 1 & 14,3 & 7 & 100,0 \\
\hline $\mathrm{SD}$ & 19 & 86,4 & 3 & 13,6 & 22 & 100,0 \\
\hline SMP & 20 & 90,9 & 2 & 9,1 & 22 & 100,0 \\
\hline SMA & 57 & 87,7 & 8 & 12,3 & 65 & 100,0 \\
\hline Diploma dan Sarjana & 23 & 88,5 & 3 & 11,5 & 26 & 100,0 \\
\hline Magister & 1 & 100,0 & 0 & 0,0 & 1 & 100,0 \\
\hline \multicolumn{7}{|l|}{ Lama Menderita DM } \\
\hline$<1$ tahun & 13 & 76,5 & 4 & 23,5 & 17 & 100,0 \\
\hline 1-5 tahun & 50 & 87,7 & 7 & 12,3 & 57 & 100,0 \\
\hline$>5$ tahun & 63 & 91,3 & 6 & 8,7 & 69 & 100,0 \\
\hline \multicolumn{7}{|l|}{ Komplikasi } \\
\hline Tidak Ada & 72 & 90,0 & 8 & 10,0 & 80 & 100,0 \\
\hline Ada & 54 & 85,7 & 9 & 14,3 & 63 & 100,0 \\
\hline
\end{tabular}

Tabel 2. menunjukkan hubungan antara dimensi locus of control dengan karakteristik responden dimana dapat disimpulkan bahwa seiring bertambahnya usia, maka penderita DM akan 
semakin internal locus of control dan cenderung bersifat stabil pada kelompok usia 46-65 tahun. Hal tersebut terlihat pada persentase responden yang lebih tinggi pada internal locus of control dibandingkan dengan external locus of control.
Berdasarkan jenis kelamin, pendidikan terakhir, lama menderita DM dan kejadian komplikasi juga diketahui persentase responden dengan internal locus of control juga lebih tinggi dibandingkan dengan external locus of control.

Tabel 3. Distribusi Background Factor Responden (n=143)

\begin{tabular}{|c|c|c|c|c|c|c|}
\hline \multirow{2}{*}{ Background Factor } & \multicolumn{2}{|c|}{ RS } & \multicolumn{2}{|c|}{ Puskesmas } & \multicolumn{2}{|c|}{ Total } \\
\hline & $\mathbf{n}$ & $\%$ & $\mathbf{n}$ & $\%$ & $\mathbf{n}$ & $\%$ \\
\hline \multicolumn{7}{|l|}{ Personality Traits } \\
\hline Introvert & 15 & 18,5 & 9 & 14,5 & 24 & 16,8 \\
\hline Moderat & 33 & 40,7 & 35 & 56,5 & 68 & 47,6 \\
\hline Ekstrovert & 33 & 40,7 & 18 & 29,0 & 51 & 35,7 \\
\hline \multicolumn{7}{|l|}{ Pendidikan } \\
\hline Background kesehatan & 54 & 66,7 & 41 & 66,1 & 95 & 66,4 \\
\hline Background non kesehatan & 27 & 33.3 & 21 & 33,9 & 48 & 33,6 \\
\hline \multicolumn{7}{|l|}{ Pengalaman } \\
\hline Menyenangkan & 6 & 7,4 & 17 & 27,4 & 23 & 16,1 \\
\hline Tidak menyenangkan & 75 & 92,6 & 45 & 72,6 & 120 & 83,9 \\
\hline \multicolumn{7}{|l|}{ Pengetahuan } \\
\hline Baik & 74 & 91,4 & 60 & 96,8 & 134 & 93,7 \\
\hline Cukup & 7 & 8,6 & 2 & 3,2 & 9 & 6,3 \\
\hline \multicolumn{7}{|l|}{ Status Ekonomi } \\
\hline Lebih dari cukup & 30 & 37,0 & 19 & 30,6 & 49 & 34,3 \\
\hline Cukup & 13 & 16,0 & 17 & 27,4 & 30 & 21,0 \\
\hline Kurang & 38 & 46,9 & 26 & 41,9 & 64 & 44,8 \\
\hline
\end{tabular}

Tabel 3. menunjukkan bahwa responden yang berada di rumah sakit cenderung memiliki personality traits yang seimbang (moderat dan ekstovert), sedangkan untuk puskesmas responden cenderung memiliki personality traits yang moderat. Responden cenderung memiliki pendidikan dengan background kesehatan, pengalaman terkait DM yang tidak menyenangkan, pengetahuan yang cenderung baik, serta status ekonomi yang cenderung kurang, baik di rumah sakit maupun puskesmas.

Tabel 4. Pengaruh Personality Traits terhadap Locus of Control Penderita DM

\begin{tabular}{|c|c|c|c|c|c|c|c|}
\hline \multirow{3}{*}{ Personality Traits } & \multicolumn{4}{|c|}{ Locus of Control } & \multirow{2}{*}{\multicolumn{2}{|c|}{ Total }} & \multirow{3}{*}{$p$} \\
\hline & \multicolumn{2}{|c|}{ External } & \multicolumn{2}{|c|}{ Internal } & & & \\
\hline & $\mathbf{n}$ & $\%$ & $\mathbf{n}$ & $\%$ & $\mathbf{n}$ & $\%$ & \\
\hline Ekstrovert & 5 & 9,8 & 46 & 90,2 & 51 & 100,0 & \multirow{4}{*}{0,004} \\
\hline Moderat & 10 & 14,7 & 58 & 85,3 & 68 & 100,0 & \\
\hline Introvert & 2 & 8,3 & 22 & 91,7 & 24 & 100,0 & \\
\hline Total & 17 & 11,9 & 126 & 88,1 & 143 & 100,0 & \\
\hline
\end{tabular}

Tabel 4. menunjukkan bahwa personality traits responden ekstrovert, moderat dan introvert lebih tinggi pada internal locus of control dibandingkan dengan external locus of control. Hasil uji statistiknya menunjukkan nilai $\rho=$ 0.004 yang berarti personality traits berpengaruh signifikan terhadap locus of control penderita DM.

Refleksi karakteristik atau personality traits penderita DM dapat dilihat berdasarkan pola pemikiran, perasaan dan ekspresi emosinya. Terkait personality traits penderita dilihat meliputi kepribadian introvert, moderat dan ekstrovert. Dimana penderita dengan kepribadian introvert cenderung lebih tenang dan tidak banyak bicara ketika diberikan kuesioner sehingga informasi yang diperoleh cukup terbatas, berbanding terbalik dengan penderita kepribadian ekstrovert yang mudah diajak berpartisipasi dan aktif dalam menceritakan kondisinya terkait dengan diabetes sehingga mempermudah dalam memperoleh informasi. Sedangkan untuk penderita dengan kepribadian moderat cenderung agak sulit ditebak sebab dalam memberikan informasi terkadang kooperatif dan terkadang juga tidak.

Menurut Eysenck (1947), perbedaan ciri kepribadian antar penderita DM disebabkan oleh kondisi fisiologis yang sebagian besar 
bersifat keturunan, sehingga yang menjadi dasar penting adalah adanya gairah dalam mengatur kesadaran, perhatian dan pengolahan informasi yang penting untuk memotivasi perilaku pengendalian penderita DM. Selain itu dopamin juga menjadi salah satu faktor fisiologis dasar penentu kepribadian penderita DM. Kadar dopamin yang tidak memadai pada penderita DM tipe 2 akan mengakibatkan penderita mengalami kecanduan gula. Hal tersebut dapat diatasi dengan mengatur pola makan dan manajemen kondisi psikis atau stress dalam mekanisme pengendalian DM.

Pengendalian dapat dilakukan dengan memilah sumber-sumber informasi yang akan sampai pada locus of control yang berasal dari internal ataupun external, kemudian dikaitkan dengan personality traits penderita. Rotter (1966), menyatakan locus of control merupakan salah satu tipe personality traits. Hal tersebut bertentangan dengan hasil penelitian ini karena locus of control diperoleh dengan didefinisikan dan diukur bukan sebagai suatu sifat, akan tetapi sebagai tempat berasalnya kontrol penderita DM terkait kemampuannya untuk mengendalikan DM.

Hal ini menandakan bahwa penderita DM memiliki implikasi untuk menunjang intervensi pengendalian penyakit diabetes. Walaupun personality traits yang dimiliki penderita bervariasi akan tetapi terhadap pusat kontrol yang mereka miliki tetap menempatkan pada internal locus of control. Sehingga intervensi pengendalian yang dilakukan dengan cara penguatan pada internal locus of control dapat ditempuh melalui melibatkan langsung penderita dalam pengendalian DM.

Tabel 5. Pengaruh Pendidikan terhadap Locus of Control Penderita DM

\begin{tabular}{|c|c|c|c|c|c|c|c|}
\hline \multirow{3}{*}{ Pendidikan } & \multicolumn{4}{|c|}{ Locus of Control } & \multirow{2}{*}{\multicolumn{2}{|c|}{ Total }} & \multirow{3}{*}{$p$} \\
\hline & \multicolumn{2}{|c|}{ Eksternal } & \multicolumn{2}{|c|}{ Internal } & & & \\
\hline & $\mathbf{n}$ & $\%$ & $\mathbf{n}$ & $\%$ & $\mathbf{n}$ & $\%$ & \\
\hline $\begin{array}{c}\text { Background non } \\
\text { kesehatan }\end{array}$ & 8 & 16,7 & 40 & 83,3 & 48 & 100,0 & \\
\hline $\begin{array}{c}\text { Background } \\
\text { kesehatan }\end{array}$ & 9 & 9,5 & 86 & 90,5 & 95 & 100,0 & 0,919 \\
\hline Total & 17 & 11,9 & 126 & 88,1 & 143 & 100,0 & \\
\hline
\end{tabular}

Tabel 5. menunjukkan bahwa responden dengan background kesehatan ataupun non-kesehatan cenderung memiliki internal locus of control yang lebih tinggi dibandingkan dengan external locus of control. Sehingga terpapar atau tidaknya seseorang dengan pendidikan kesehatan, tetap akan cenderung memiliki internal locus of control yang lebih tinggi. Hasil uji statistiknya menunjukkan nilai $\rho=$ 0.919 yang berarti pendidikan berpengaruh tidak signifikan terhadap locus of control penderita DM.

Pendidikan yang dimaksudkan disini bukan hanya melihat dari tingkat pendidikan formal yang ditempuh penderita, akan tetapi juga proses pembelajaran yang didapatkan untuk memperoleh pengetahuan terkait penyakitnya. Penderita DM dengan background kesehatan artinya pernah menempuh pendidikan formal dalam bidang kesehatan dan/atau pernah terpapar penyuluhan kesehatan terkait penyakitnya. Sedangkan untuk penderita DM dengan background non-kesehatan artinya tidak pernah menempuh pendidikan formal dalam bidang kesehatan dan/atau terpapar penyuluhan kesehatan terkait penyakitnya. Sehingga penderita dengan background kesehatan cenderung melakukan pengendalian DM lebih baik dibandingkan penderita dengan background non-kesehatan.

Pendidikan secara spesifik dapat mengarahkan individu pada internal locus of control sebab pendidikan memberikan kontribusi pada dimensi locus of control sehingga penderita akan mampu melakukan pengendalian setelah sering terpapar terkait masalah kesehatan (Kemenkes, 2013). Sebab penderita yang jarang terpapar terkait masalah kesehatan akan sangat sulit dalam melakukan pengendalian, maka penderita kemudian akan pasrah terhadap nasib dan lebih mengarah pada external locus of control. Akan tetapi berdasarkan hasil penelitian yang ditemukan menunjukkan bahwa pendidikan berpengaruh tidak signifikan terhadap locus of control, maka dapat dikatakan bahwa pendidikan responden dari backrground kesehatan ataupun non-kesehatan tidak memiliki perbedaan dimensi pada locus of control dan cenderung pada internal locus of control. 
Penelitian Grossi (2000), menyatakan bahwa pendidikan kesehatan pada penderita DM merupakan sumber utama dalam mengontrol penyakitnya akan tetapi tidak selalu berkontribusi dalam perbaikan kadar glikemik penderita. Pendidikan terhadap locus of control akan berguna untuk memberdayakan penderita dan menambah keyakinan dalam melakukan pengendalian. Akan tetapi tingkat pendidikan yang tinggi tidak menjadi jaminan dalam melakukan pengendalian DM dengan baik.

Tabel 6. Pengaruh Pengalaman terhadap Locus of Control Penderita DM

\begin{tabular}{|c|c|c|c|c|c|c|c|}
\hline \multirow{3}{*}{ Pengalaman } & \multicolumn{4}{|c|}{ Locus of Control } & \multirow{2}{*}{\multicolumn{2}{|c|}{ Total }} & \multirow{3}{*}{$p$} \\
\hline & \multicolumn{2}{|c|}{ External } & \multicolumn{2}{|c|}{ Internal } & & & \\
\hline & $\mathbf{n}$ & $\%$ & $\mathbf{n}$ & $\%$ & $\mathbf{n}$ & $\%$ & \\
\hline Tidak Menyenangkan & 14 & 11,7 & 106 & 88,3 & 120 & 100,0 & \multirow{3}{*}{0,043} \\
\hline Menyenangkan & 3 & 13,0 & 20 & 87,0 & 23 & 100,0 & \\
\hline Total & 17 & 11,9 & 126 & 88,1 & 143 & 100,0 & \\
\hline
\end{tabular}

Tabel 6. menunjukkan bahwa pengalaman yang dirasakan responden terkait penyakit DM baik meliputi pengalaman diri sendiri, keluarga dan orang lain secara menyenangkan maupun tidak menyenangkan cenderung memiliki internal locus of control yang lebih dominan dibandingkan dengan external locus of control. Hasil uji statistiknya menunjukkan nilai $\rho=0.043$ yang berarti bahwa pengalaman berpengaruh signifikan terhadap locus of control penderita DM.

Pengalaman yang merupakan peristiwa yang pernah dialami terkait DM baik dari pribadi penderita itu sendiri, keluarga (riwayat keluarga) dan orang lain yang berada di sekitar penderita. Cakupan tersebut dipilih berdasarkan pengalaman menyenangkan maupun yang tidak menyenangkan bagi penderita. Pengendalian DM oleh penderita akan lebih efektif jika ada komitmen untuk mencegah terulangnya pengalaman yang tidak menyenangkan dengan melibatkan locus of control.

Schneider (1971); Nowicki \& Strickland (1973), memaparkan bahwa pengalaman terkait dengan kejadian yang kurang menyenangkan dapat meningkatkan locus of control dan jika menyenangkan dapat meningkatkan internal locus of control. Pernyataan tersebut bertentangan dengan hasil yang diperoleh dikarenakan penderita DM cenderung internal locus of control dimana peristiwa yang pernah dialami akan lebih meningkatkan kesadaran penderita DM akan perlunya kontrol dari dalam diri. Temuan tersebut mendukung hipotesis bahwa pengalaman berpengaruh terhadap locus of control.

Tabel 7. Pengaruh Pengetahuan terhadap Locus of Control Penderita DM

\begin{tabular}{|c|c|c|c|c|c|c|c|}
\hline \multirow{3}{*}{ Pengetahuan } & \multicolumn{4}{|c|}{ Locus of Control } & \multirow{2}{*}{\multicolumn{2}{|c|}{ Total }} & \multirow{3}{*}{$p$} \\
\hline & \multicolumn{2}{|c|}{ Eksternal } & \multicolumn{2}{|c|}{ Internal } & & & \\
\hline & $\mathbf{n}$ & $\%$ & $\mathbf{n}$ & $\%$ & $\mathbf{n}$ & $\%$ & \\
\hline Cukup & 1 & 11,1 & 8 & 88,9 & 9 & 100,0 & \multirow{3}{*}{0,640} \\
\hline Baik & 16 & 11,9 & 118 & 88,1 & 134 & 100,0 & \\
\hline Total & 17 & 11,9 & 126 & 88,1 & 143 & 100,0 & \\
\hline
\end{tabular}

Tabel 7. menunjukkan bahwa responden dengan pengetahuan yang tergolong cukup dan baik terkait pengendalian DM cenderung memiliki internal locus of control yang lebih dominan dibandingkan dengan external locus of control. Hasil uji statistiknya menunjukkan nilai $\rho$ $=0.640$ yang berarti pengetahuan berpengaruh tidak signifikan terhadap locus of control penderita DM.

Informasi yang telah diketahui penderita DM terkait penyakitnya hingga cara pengendaliannya merupakan pengetahuan yang diukur. Pengetahuan tersebut dapat diperoleh dari berbagai sumber seperti dari tenaga kesehatan, keluarga, orang lain maupun media sosial, baik berupa penyuluhan, sharing atau bahan bacaan langsung. Pengetahuan merupakan hal yang berkaitan erat dengan pendidikan. Dimana penderita yang terpapar dengan pendidikan kesehatan akan memiliki pengetahuan yang lebih baik terkait pengendalian DM. 
Penelitian Seeman \& Evans (1962), mengatakan bahwa terdapat kaitan antara pengetahuan seseorang tentang penyakitnya dengan internal locus of control.

Sedangkan penelitian Goodfellow et al., (1996), mengatakan bahwa pengetahuan dan locus of control penderita DM tidak terkait secara signifikan dengan manajemen diri seperti pemberian obat, pengukuran kadar glukosa, diet dan perawatan kaki.

Pengetahuan yang berkontribusi pada dimensi locus of control membuat penderita mampu melakukan pengendalian setelah memahami informasi terkait penyakitnya, sedangkan akan berbanding terbalik dengan penderita yang tidak memahami informasi terkait DM. Hal tersebut disebabkan oleh penderita DM tidak memiliki pengetahuan yang cukup untuk mencegah perkembangan penyakit ke arah komplikasi dan akan mengandalkan bantuan orang lain dalam pencegahan dan pengobatannya (external locus of control).

Tabel 8. Pengaruh Status Ekonomi terhadap Locus of Control Penderita DM

\begin{tabular}{cccccccc}
\hline \multirow{2}{*}{$\begin{array}{c}\text { Status } \\
\text { Ekonomi }\end{array}$} & \multicolumn{4}{c}{ Locus of Control } & \multicolumn{2}{c}{ Total } & \\
\cline { 2 - 5 } & \multicolumn{2}{c}{ Eksternal } & \multicolumn{2}{c}{ Internal } & & & \\
\cline { 2 - 6 } & $\mathbf{n}$ & $\%$ & $\mathbf{n}$ & $\%$ & $\mathbf{n}$ & $\%$ & \\
\hline Kurang & 8 & 12,5 & 56 & 87,5 & 64 & 100,0 & \\
\hline Cukup & 3 & 10,0 & 27 & 90,0 & 30 & 100,0 & \\
\hline $\begin{array}{c}\text { Lebih dari } \\
\text { Cukup }\end{array}$ & 6 & 12,2 & 43 & 87,8 & 49 & 100,0 & 0,119 \\
\hline Total & 17 & 11,9 & 126 & 88,1 & 143 & 100,0 & \\
\hline
\end{tabular}

Tabel 8. menunjukkan bahwa responden cenderung memiliki internal locus of control lebih dominan dibandingkan dengan external locus of control baik pada responden berstatus ekonomi kurang, cukup dan lebih dari cukup. Hasil uji statistiknya menunjukkan nilai $\rho=0.119$ yang berarti status ekonomi berpengaruh tidak signifikan terhadap locus of control penderita DM.

Status ekonomi berkontribusi pada dimensi locus of control dalam melakukan pengendalian DM, dimana penderita DM yang status ekonominya tergolong lebih dari cukup akan memiliki kepercayaan diri yang tinggi terhadap kemampuannya untuk melakukan pengobatan dan perawatan. Penderita akan cenderung internal locus of control walaupun tingkat status ekonominya kurang, sehingga temuan yang diperoleh menunjukkan bahwa status ekonomi berpengaruh tidak signifikan terhadap locus of control. Sebab kontrol yang berasal dari dalam diri penderita DM tidak dipengaruhi oleh banyak kurangnya pemasukan bulanan, karena dalam melakukan pengendalian DM tidak membutuhkan biaya yang besar.

Tetapi hal tersebut bertentangan dengan hasil temuan Pinto, Mansfield, \& Parente (2004), mengatakan bahwa seseorang yang sejahtera dalam segi finansial memiliki internal locus of control yang tinggi sebab mampu menghadirkan segala yang diinginkannya. Hasil tersebut sejalan dengan studi yang dilakukan Hayes, Luoma, Bond, Masuda, \& Lillis (2006), menyimpulkan bahwa individu yang mengalami kesulitan finansial lebih mungkin untuk mempertimbangkan hal tersebut sebagai sumber daya dan akan cenderung memiliki external locus of control yang lebih tinggi. Walaupun demikian dengan hasil penelitian ini dapat menjadi sebuah bahan pertimbangan untuk mengubah pola pikir bahwa status ekonomi bukan menjadi penentu utama penderita DM untuk bisa melakukan tindakan pengendalian yang berhubungan dengan penyakitnya.

\section{Kesimpulan dan Saran}

Berdasarkan background factor responden, dapat disimpulkan bahwa determinan yang berpengaruh signifikan terhadap locus of control adalah personality traits dan pengalaman. Penderita dengan kepribadian introvert, ekstrovert maupun moderat akan dominan internal locus of control daripada external locus of control. Begitupun dengan pengalaman yang dimiliki. Menyenangkan atau tidak menyenangkan pengalaman yang dimiliki penderita akan dominan internal locus of control daripada external locus of control dalam melakukan pengendalian DM. Disarankan agar perlu meningkatkan keterlibatan penderita dalam mengisi locus of control dengan cara mencari informasi dan memperluas jaringan sosial, sehingga terpenuhi banyak sumber yang bisa 
meningkatkan persepsi dan membentuk perilaku pengendalian DM.

\section{Ucapan terima kasih}

Terima kasih kepada, Stikes Nani Hasanuddin Makassar yang telah banyak membantu dalam terlaksananya penelitian ini, rumah sakit dan puskesmas tempat penelitian, tim penyusun serta semua pihak yang terlibat dalam penelitian ini.

\section{Daftar Pustaka}

Ajzen, I. (2014). Laws of human behavior: Symmetry, compatibility, and, (January 2005).

EYSENCK, H. J. (1947). STUDENT SELECTION BY MEANS OF PSYCHOLOGICAL TESTS???A CRITICAL SURVEY. British Journal of Educational Psychology.

Goodfellow, J., Ramsey, M. W., Luddington, L. A., Jones, C. J., Coates, P. A., Dunstan, F., ... Henderson, A. H. (1996). Endothelium and inelastic arteries: an early marker of vascular dysfunction in non-insulin dependent diabetes. BMJ (Clinical Research Ed.).

Grossi, S. (2000). Smoking and stress: common denominators for periodontal disease, heart disease, and diabetes mellitus. Compendium of Continuing Education in Dentistry. (Jamesburg, N.J. : 1995). Supplement.

Hayes, S. C., Luoma, J. B., Bond, F. W., Masuda, A., \& Lillis, J. (2006). Acceptance and Commitment Therapy: Model, processes and outcomes. Behaviour Research and Therapy.

Kemenkes. (2013). Hasil Riset Kesehatan
Dasar 2013. Jakarta: Kementerian Kesehatan RI.

Kheir, N., Cuppens-Boulahia, N., Cuppens, F., \& Debar, H. (2010). A service dependency model for cost-sensitive intrusion response. In Lecture Notes in Computer Science (including subseries Lecture Notes in Artificial Intelligence and Lecture Notes in Bioinformatics).

Nowicki, S., \& Strickland, B. R. (1973). A locus of control scale for children. Journal of Consulting and Clinical Psychology.

Pinto, M. B., Mansfield, P. M., \& Parente, D. H. (2004). Relationship of Credit Attitude and Debt to Self-Esteem and Locus of Control in College-Age Consumers. Psychological Reports.

Rotter, J. B. (1966). Generalized expectancies for internal versus external control of reinforcement. Psychological Monographs, 80(1), 1-28.

Schneider, S. W. (1971). A comparison of canal preparations in straight and curved root canals. Oral Surgery, Oral Medicine, Oral Pathology.

Seeman, M., \& Evans, J. W. (1962). Alienation and Learning in a Hospital Setting. American Sociological Review, 27(6), 772 .

Soegondo, S. (2015). Penatalaksanaan Diabetes Melitus Terpadu. : FKUI.

Wallston, K. (2001). Conceptualization and Operationalization of Perceive $\mathrm{d}$ Control. Handbook of Health Psychology.

Wallston, K. A. (1981). Health locus of control scales. Research with the Locus of Control.

WHO. (2015). Obesity and overweight. Fact sheet 311. 